\title{
PEMBELAJARAN MENULIS LAPORAN DENGAN TEKNIK KOOPERATIF TERPADU MEMBACA DAN MENULIS SMPN 1 GEBANG
}

\author{
Sri Atin \\ SMPN 1 Gebang Kabupaten Cirebon, Jawa Barat, Indonesia \\ Email: Sri.atin0118@gmail.com
}

\begin{abstract}
This study aims to improve the ability of grade IX students at SMPN 1 Gebang Cirebon Regency in understanding Indonesian subjects in the subject of "Technology" with the subject "Writing Reports" through the application of the Integrated Reading and Writing Cooperative Technique, so that learning Indonesian becomes more enjoyable and creates creativity. The method used was Classroom Action Research (PTK) which was carried out in class IX SMPN 1 Gebang Cirebon Regency. Activities carried out in two cycles of action. The results showed that the application of the Integrated Reading and Writing Cooperative Technique could improve students' understanding in learning Indonesian "Writing Report" in class IX of SMPN 1 Gebang Cirebon
\end{abstract}

Keywords: learning outcomes, integrated cooperative techniques, reading and writing

\begin{abstract}
Abstrak
Penelitian ini bertujuan untuk meningkatkan kemampuan siswa kelas IX SMPN 1 Gebang Kabupaten Cirebon dalam memahami mata pelajaran Bahasa Indonesia pada materi "Teknologi" dengan pokok bahasan "Menulis Laporan" melalui penerapan Teknik Kooperatif Terpadu Membaca dan Menulis, sehingga pembelajaran Bahasa Indonesia menjadi lebih menyenangkan dan menimbulkan kreatifitas. Metode yang digunakan adalah Penelitian Tindakan Kelas (PTK) dengan dilaksanakan pada k kelas IX SMPN 1 Gebang Kabupaten Cirebon. Kegiatan dilakukan sebanyak dua siklus tindakan. Hasil penelitian menunjukkan penerapan Teknik Kooperatif Terpadu Membaca dan Menulis dapat Meningkatkan Pemahaman siswa dalam belajar Bahasa Indonesia "Menulis Laporan" di kelas IX SMPN 1 Gebang Kabupaten Cirebon.
\end{abstract}

Kata Kunci: hasil belajar, teknik kooperatif terpadu, membaca dan menulis

DOI: $\underline{\text { https://doi.org/10.31943/bi.v6i1.99 }}$

\section{How to Cite}

Atin, S. (2021). PEMBELAJARAN MENULIS LAPORAN DENGAN TEKNIK KOOPERATIF TERPADU MEMBACA DAN MENULIS SMPN 1 GEBANG. Bahtera Indonesia; Jurnal Penelitian Bahasa Dan Sastra Indonesia , 6(1), 56-65. https://doi.org/10.31943/bi.v6i1.99 


\section{PENDAHULUAN}

Menulis berarti menuangkan ide, pikiran, gagasan, pengetahuan, dan wawasan ke dalam tulisan yang sistematis dan bisa dipahami oleh orang lain. Menulis merupakan suatu kegiatan yang produktif dan ekspresif (Juidah, 2016).

Menumbuhkan sumber daya manusia yang berkualitas diperlukan manusia-manusia yang berprestasi. Untuk mencapai prestasi tentunya harus memiliki kemampuankemampuan dasar yang menjadi prasat dalam budang studi. Oleh karena itu, guru sebagai pemeran utama dalam mendidik serta mengajar bangsa diupayakan agar selalu mengadakan perbaikan atau inovasi dalam pembelajaran, baik metode maupun media pembelajaran. Penggunaan metode pembelajaran oleh guru pada umunya bersifat tetap, artinya guru hanya menggunakan metode yang sama dalam menyampaikan materi tertentu, tidak berusaha mencoba menggunakan metode lain untuk mengajarkan. Hal ini disebabkan enggan untuk mencoba atau mencari alternative penggunaan metode lain untuk mengajarkan materi pembelajaran yang sama. Pola seperti ini menyebabkan guru merasa bosan dengan studinya.

Namun, pada kenyataannnya kemampuan menulis teks berita siswa masih rendah. Hal tersebut berdasarkan data nilai menulis teks berita yang diperoleh dari guru mata pelajaran, hanya 16 siswa (32\%) dari 50 siswa yang nilai menulisnya yang sudah mencapai standar ketuntasan minimal (Juidah, 2016).

Berdasarkan pernyataan di atas, jelas sekali bahwa eksistensi guru merupakan elemen bangsa yang sangat urgent dan vital serta kunci utama bagi kemajuan bangs aitu sendiri terutama dalam bidang Pendidikan. Meskipun guru dalam mata rantai proses Pendidikan tidak berdiri sendiri, karena masih ada factor lainnya sangat mempengaruhi, tetapi guru merupakan factor kunci yang menggembangkan motivasi belajar siswa.

Kenyataan dilapangan, di SMP Negeri 1 Gebang khususnya dalam Mata Pelajaran Bahasa Indonesia, kegiatan pembelajaran masih belum menunjukkan pengembangan motivasi belajar siswa yang baik. Pembelajaran lebih ditekankan pada model yang banyak diwarnai dengan ceramah dan bersifat guru sentries. Hal ini mengakibatkan siswa kurang terlibat dalam kegiatan pembelajaran. Kegiatan siswa hanya duduk, diam, dengar, catat dan hafal. Kegiatan ini mengakibatkan siswa kurang ikut berpartisipasi dalam kegiatan pembelajaran yang cenderung menjadikan mereka cepat bosan dan malas belajar. Melihat kondisi demikian, maka perlu adanya alternative pembelajaran yang berorientasi pada 
bagaimana siswa belajar sendiri informasi,

Dari

permasalahan

yang

mengembangkan topik yang sudah dipelajari dan yang akan dipelajari dalam kehidupan sehari-hari. Serta dapat berinteraksi multi arah baik Bersama guru maupun Bersama siswa dalam suasana yang menyenangkan dan bersahabat. Sehingga hasil belajar yang diperoleh di bawah standar KKM yaitu 70, berarti hal ini menunjukkan bahwa kegiatan proses pembelajaran Bahasa Indonesia belum berhasil secara maksimal.

Sejalan dengan persoalan di atas dalam proses belajar mengajar Bahasa Indonesia diperlukan metode-metode baru yang inovatif yang dapat membawa siswa kearah belajar yang lebih baik dan bersemangat tinggi. Oleh karena itu harus dicari metode-metode baru yang tepat yang dapat menarik siswa kearah belajar yang lebih baik dan bersemangat dalam mempelajari Bahasa Indonesia, salah satunya adalah teknik kooperatif terpadu membaca dan menulis. Beberapa penelitian yang telah dilaksanakan, diantaranya oleh Saputri, dkk. (2016), Niliawati (2018), Sampepolan (2019) menunjukan penerapan teknik kooperatif terpadu membaca dan menulis dapat meningkatkan kemampuan menulis dan hasil belajar siswa. Atas dasar itulah penulis memilih teknik ini sebagai upaya meningkatkan kemampuan menulis siswa dikemukakan diatas, perlu dicari strategi baru dalam pembelajaran yang melibatkan siswa secara aktif, pembelajaran yang mengutamakan penguasaan kompetensi harus berpusat pada siswa (Focus on learners), memberikan pembelajaran dan pengelaman belajar yang relevan dan kontekstual dalam kehidupan nyata (provide relevant and contextualized subject matter) dan mengembangkan mental yang kaya dan kuat pada siswa.

Disini guru Bahasa Indonesia dituntut untuk merancang kegiatan pembelajaran yang mampu menyampaiakn pengetahuan dan keterampilan berbahasa yang diperoleh, berguna dalam komunikasi sehari-hari, agar dihindari penyajian materi (khususnya kebahasaan) yang tidak bermanfaat dalam komunikasi sehari-hari, menekankan bahwa melalui pengajaran Bahasa Indonesia, siswa diharapkan mampu menangkap ide yang diungkapkan dalam Bahasa Indonesia, baik lisan maupun tulisan, serta mampu mengungkapkan gagasan dalam Bahasa Indonesia, baik secara lisan maupun tulisan. Penilaian hanya sebagai sarana pembelajaran Bahasa, bukan sebagai tujuan, mengharapkan agar di kelas terjadi suasana interaktif secara tercipta masyarakat pemakaian Bahasa yang produktif. Tidak ada peran guru yang dominan. Guru diharapkan sebagai "pemicu” 
kegiatan berbahasa lisan maupun tulisan. Peran guru sebagai orang yang tahu atau pemberi informasi pengetahuan Bahasa Indonesia agar dihindari.

Tujuan penerapan teknik kooperatif terpadu membaca dan menulis, diharapkan untuk mencapai setidak-tidaknya tiga tujuan

\section{METODE PENELITIAN}

Penelitian ini merupakan Penelitian Tindakan Sekolah yang dilakukan secara kolaborasi. Penelitian tindakan sekolah berdasarkan pendapat Sanjaya (2011: 26) adalah proses pengkajian masalah pembelajaran di dalam kelas melalui refleksi diri dalam upaya untuk memecahkan masalah tersebut dengan cara melakukan tindakan yang terencana dalam situasi nyata serta menganalisis setiap pengaruh dari perlakuan tersebut. Pendapat tersebut sesuai pendapat yang disampaikan oleh Kasbolah (2001: 15), bahwa Penelitian tindakan sekolah merupakan penelitian tindakan dalam bidang pendidikan yang dilaksananakan dalam kawasan kelas dengan tujuan untuk memperbaiki dan atau meningkatkan kualitas pembelajaran. Banyak model Penelitian Tindakan Sekolah yang dapat diterapkan, tetapi dalam penelitian ini menggunakan model Kemmis dan McTaggart di mana dalam perencanaannya menggunakan siklus sistem spiral yang di dalamnya terdiri dari empat komponen, yaitu rencana, tindakan dan observasi serta refleksi (Sujati, 2000: 23) pembelajaran, yaitu hasil belajar akademik, penerimaan terhadap keragaman, dan mengembangan keterampilan social. Bebrapa ahli berpendapat bahwa pembelajaran ini unggul dalam membantu siswa memahami konsep-konsep sulit.

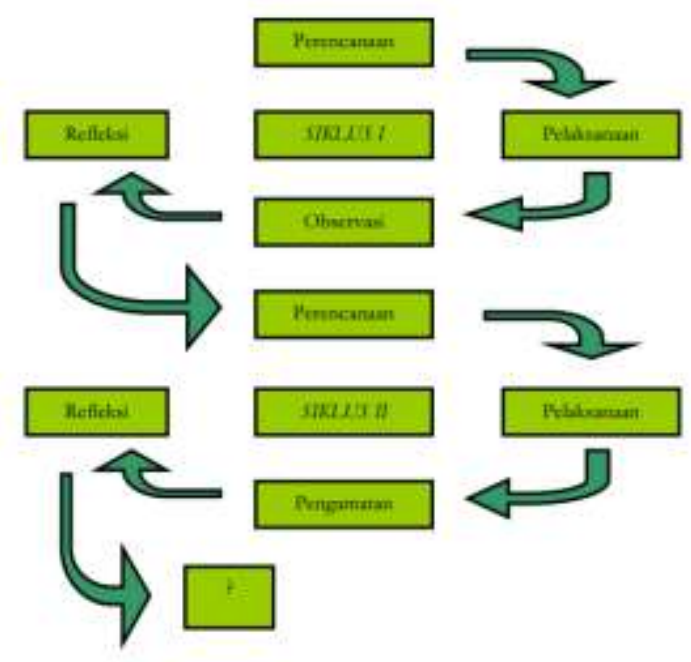

laggart

\section{Subyek Penelitian}

Subjek penelitian tindakan kelas ini adalah siswa kelas IXH SMP Negeri 1 Gebang Tahun ajaran 2017-2018 dalam pengambilan subjek penelitian ini didasarkan pada kondisi siswa kelas IX-H secara keseluruhan berjumlah 36 siswa, karena asumsikan karakteristik dan kemampuan dianggap sama.

\section{Prosedur Penelitian}

Prosedur penelitian Tindakan kelas dilakukan dengan dua siklus, dan tiap siklus dilaksanakan sesuai dengan perubahan yang 
dicapai, sesuai disain faktor yang diteliti.

Untuk mengetahui efektifitas pembelajaran di

SMP Negeri 1 Gebang Kabupaten Cirebon

Kelas IXH dilakukan observasi terhadap kegiatan pembelajaran yang dilakukan oleh guru, diadakan wawancara baik dengan guru maupun siswa. Melalui kegiatan ini dapat dilakukan musyawarah antara guru dengan observer untuk menetapkan Tindakan paling tepat dalam rangka meningkatkan efektifitas pembelajaran di kelas IXH.

Hasil wawancara guru kelas, Langkah yang paling tepat adalah meningkatkan aktivitas dan peran serta siswa dalam proses pembelajaran tersebut dengan melatih dan mengembangkan keterampilan intelektual siswa.

Dengan berpatok pada refleksi awal tersebut, maka prosedur pelaksanaan Tindakan kelas ini meliputi: (1) perencanaan. (2) pelaksanaan tindakan, (3) Observer, (4) refleksi dalam setiap siklus.

HASIL DAN PEMBAHASAN
Secara garis besar kegiatan pembelajaran pada penelitian ini dilaksanakan dalam 2 siklus, masing-masing siklus terdiri dari studi pendahuluan, perencanaan, Tindakan, observer dan refleksi terhadap kegiatan yang dilaksanakan.

Penelitian pada siklus ini dilakukan dengan: (a) identifikasi permasalahan menyangkut bahan pelajaran yang digunakan, strategi pembelajaran yang digunakan. Pada siklus ini menggunakan pendekatan konvensional, (b) menyajikan materi pembelajaran "Menulis Laporan",(c) melakukan pengamatan dengan menggunakan obrevasi dan pemotretan, (d) mengukur dampak pendekatan konvensional digunakan daftar aktifitas siswa.

Dari table 1 dapat disimpulkan bahwa kemampuan guru dalam mengajar, sikap guru dalam pelajaran, penguasaan materi, proses pembelajaran, pemakaian media, kemampuan menutup pelajaran dinilai cukup (C) oleh observer.

Tabel 1. Hasil Observasi Kinerja Guru dalam Proses Pembalajaran Siklus I

\begin{tabular}{lllllllll}
\hline N & \multirow{2}{*}{ Aspek yang Dinilai } & Y & Tida & \multicolumn{5}{c}{ Penilaian } \\
o & a & $k$ & 1 & 2 & 3 & 4 & 5 \\
\hline
\end{tabular}

\section{Pengamatan Kegiatan Belajar}

A Mengajar

1. Kegiatan Awal

a. Mengaitkan pelajaan sekarang dengan yang lalu

b. Menyampaikan tujuan pembelajaran

c. Memotivasi siswa

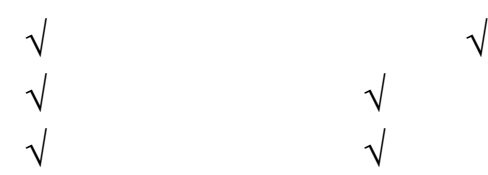

2. Kegiatan Inti 
a. Mempresentasikan informasi

b. mengorganisasikan siswa

c. membimbing siswa

1) Diskusi kelompok

2) Mengajukan pertanyaan

3) Menjawab / menanggapi pertanyaan

4) Menyampaikan ide / pendapat

5) memperhatikan secara aktif

6) Bekerja dan belajar bersama

d. memberikan test/ evaluasi

e. Memberikan pengakuan / penghargaan

f. Menggunakan alat peraga

\section{Kegiatan Akhir}

a. Membimbing siswa untuk merangkum

b. Memberikan PR sebagai pengayaan

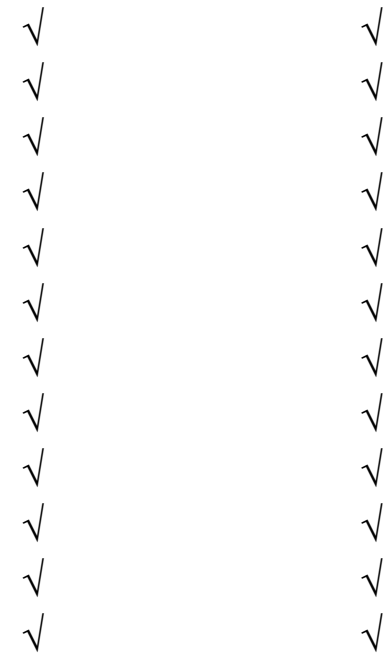

B Suasana Kelas

1. siswa antuasias

2. Guru antusias

3. Waktu sesuai dengan alokasi

4. KBM sesuai dengan RPP

Jumlah

$\begin{array}{ll}\sqrt{ } & \sqrt{ } \\ \sqrt{ } & \sqrt{ }\end{array}$

Rata-rata

$\begin{array}{cr}\sqrt{ } & \sqrt{ } \\ \sqrt{ } & \sqrt{ } \\ \sqrt{ } & \sqrt{ } \\ \sqrt{ } & \sqrt{ } \\ & 50: 100 \times 100 \%=50 \% \\ & 50: 20=2,5=\text { cukup }\end{array}$

Dari hasil table 2 ditas disimpulkan menyampaikan pendapat, memperhatikan bahwa perhatioan siswa dalam Kegiatan materi pembelajaran, bekerja dan belajar Belajar Mengajar (KBM), keberanian siswa secara aktif dinilai observer adalah cukup dalam mengajukan, menjawab pertanyaan, (C).

Table 2. Hasil Observasi Kinerja Siswa dalam proses Pembelajaran Siklus I

\begin{tabular}{|c|c|c|c|c|c|c|c|}
\hline \multirow{2}{*}{ No } & \multirow{2}{*}{ Aspek yang diminati } & \multicolumn{5}{|c|}{ Analisis Hasil dicapai } & \multirow{2}{*}{ Ket } \\
\hline & & 1 & 2 & 3 & 4 & 5 & \\
\hline 1 & Mengajukan Pertanyaan & & $\sqrt{ }$ & & & & \\
\hline 2 & Menjawab Pertanyaan & & $\sqrt{ }$ & & & & \\
\hline 3 & Menyampaikan Pendapat & & & $\sqrt{ }$ & & & \\
\hline 4 & Memperhatikan secara aktif & & & $\sqrt{ }$ & & & \\
\hline 5 & Bekerja dan belajar secara aktif & & & $\sqrt{ }$ & & & \\
\hline \multicolumn{2}{|c|}{ Jumlah } & & & 12 & & & $12: 25 \times 100 \%=$ \\
\hline \multicolumn{2}{|c|}{ Rata - rata } & & $: 5=$ & $2,4=$ & Cukı & & $48 \%$ \\
\hline
\end{tabular}

Penelitian pada siklus II dilakukan menyangkut bahan pelajaran yang digunakan, dengan: a) identifikasi permasalahan strategi pembelajaran yang biasa digunakan, 
b) menyajikan materi Menulis Laporan, c)

Dari hasil table 3 diatas dapat melakukan pengamatan dengan menggunakan disumpulkan bahwa perhatian siswa dalam observer dan pemotretan sebagai evaluasi Kegiatan Belajar Mengajar (KBM), pembelajaran. keberanian siswa dalam mengajukan

Proses pembelajaran yang dilakukan pertanyaan, menyampaikan pendapat, guru dalam menyajikan materi tentang memperhatikan materi pembelajaran, bekerja Menulis Laporan, bahwa siswa memahami dan be;ajar secara aktif dinilai pbserver adalah karena melatih dan menjawab soal berulang- Baik Sekali. ulang yang telah dibagikan oleh guru.

Tabel 3. Hasil Observasi Kinerja Siswa dalam proses Pembelajaran Siklus II

\begin{tabular}{|c|c|c|c|c|c|c|c|}
\hline \multirow{2}{*}{ No } & \multirow{2}{*}{ Aspek yang diminati } & \multicolumn{5}{|c|}{ Analisis Hasil dicapai } & \multirow{2}{*}{ Ket } \\
\hline & & 1 & 2 & 3 & 4 & 5 & \\
\hline 1 & Mengajukan Pertanyaan & \multicolumn{5}{|c|}{$\sqrt{ }$} & \\
\hline 2 & Menjawab Pertanyaan & \multicolumn{5}{|c|}{$\sqrt{ }$} & \\
\hline 3 & Menyampaikan Pendapat & \multicolumn{5}{|c|}{$\sqrt{ }$} & \\
\hline 4 & Memperhatikan secara aktif & \multicolumn{5}{|c|}{$\sqrt{ }$} & \\
\hline 5 & Bekerja dan belajar secara aktif & \multicolumn{5}{|c|}{$\sqrt{ }$} & \\
\hline \multicolumn{2}{|c|}{ Jumlah } & \multicolumn{5}{|c|}{19} & $19: 25 \times 100 \%=76 \%$ \\
\hline \multicolumn{2}{|c|}{ Rata - rata } & \multicolumn{5}{|c|}{$19: 5=3,8=$ Baik Sekali } & \\
\hline
\end{tabular}

Table 4. Hasil Observasi Kinerja Guru dalam Proses Pembelajaran Siklus II

\begin{tabular}{lllllllll}
\hline \multirow{2}{*}{ No } & Aspek yang Dinilai & Ya & Tidak & \multicolumn{4}{c}{ Penilaian } \\
& & & 1 & 2 & 3 & 4 & 5 \\
\hline
\end{tabular}

A Pengamatan Kegiatan Belajar Mengajar

\section{Kegiatan Awal}

a. Mengaitkan pelajaan sekarang dengan yang lalu

b. Menyampaikan tujuan pembelajaran

c. Memotivasi siswa

\section{Kegiatan Inti}

a. Mempresentasikan informasi

b. mengorganisasikan siswa

c. membimbing siswa

1) Diskusi kelompok

2) Mengajukan pertanyaan

3) Menjawab / menanggapi pertanyaan

4) Menyampaikan ide / pendapat

5) memperhatikan secara aktif

6) Bekerja dan belajar bersama

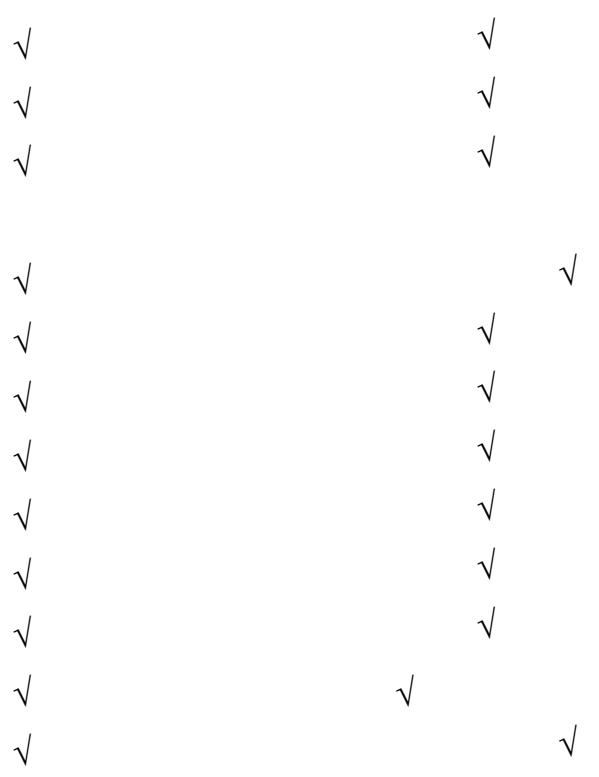


d. memberikan test/ evaluasi

e. Memberikan pengakuan / penghargaan

f. Menggunakan alat peraga

\section{Kegiatan Akhir}

a. Membimbing siswa untuk merangkum

b. Memberika PR sebagai pengayaan

\section{B Suasana Kelas}

1. siswa antuasias

2. Guru antusias

3. Waktu sesuai dengan alokasi

4. KBM sesuai dengan RPP

Jumlah

$100 \times 100 \%=92 \%$

Rata-rata

92: $20=4,5=$ Baik Sekali

Dari table diatas dapat disimpulkan bahwa kemampuan guru dalam pelajaran, sikap guru dalam pelajaran, penguasaan materi, proses pembelajaran, pemekaian media, kemampuan munutup pelajaran dinilai baik (B) oleh observer.

Dari kegiatan pembelajaran Bahasa Indonesia pada materi "Menulis Laporan" dengan menerapkan Teknik Kooperatif Terpadu Membaca dan Menulis di kelas IXH SMP Negeri 1 Gebang Kabupten Cirebon, ditemukan atau diperoleh hasil evaluasi selama siklus I dan II yaitu

Tingkat pencapaian pengasaan materi pembelajaran Bahasa Indonesia "Menulis Laporan" mengalami peningkatan yaitu pada awal sebelumnya adanya Tindakan mencapai rata-rata 54,77, pada siklus I naik mencapai rata-rata 67,15 , dan pada siklus II ada peningkatan mencapai rata-rata 80.84 Hasil evaluasi dari kerja kelompok dalam pembahasan materi "Menulis Laporan" pada siklus I memperoleh rat-rata 70 dan pada siklus II naik menjadi 85 .

Tabel 5. Nilai Evaluasi Belajar Kelompok Siklus I dan II

\begin{tabular}{rlrrl}
\hline \multirow{2}{*}{ No } & \multirow{2}{*}{$\begin{array}{c}\text { Nama } \\
\text { Kelompok }\end{array}$} & \multicolumn{2}{c}{ Nilai Evaluasi } & Keterangan \\
\cline { 3 - 5 } & Siklus I & \multicolumn{2}{c}{$\begin{array}{l}\text { Siklus } \\
\text { II }\end{array}$} & \\
\hline 1 & I & 70 & 80 & Naik \\
2 & II & 70 & 90 & Naik \\
3 & III & 60 & 80 & Naik \\
4 & IV & 70 & 90 & Naik \\
5 & V & 80 & 90 & Naik \\
6 & VI & 70 & 80 & Naik \\
\hline \multirow{2}{*}{ SIMPJylah N } & $\mathbf{4 2 0}$ & $\mathbf{5 1 0}$ & \\
\hline
\end{tabular}

Berdasarkan penjelasan diatas dapat disimpulkan bahwa hipotesis Tindakan terbukti, yaitu penerapan Teknik Kooperatif terpadu Membaca dan Menulis dapat Meningkatkan Pemahaman siswa Kelas IXH SMP Negeri 1 Gebang Kabupaten Cirebon dalam belajar Bahasa 
Indonesia pada materi "Menulis Laporan" dan hasil belajarnya.

Penelitian ini juga mendukung penelitian sebelumnya seperti penelitian (Sutisno, 2017) yang membahas tentang pemanfaatan metode pembelajaran terutama metode resitasi bisa digunakan dalam pembelajaran menulis puisi serta materi lain yang membutuhkan waktu lama untuk mengerjakan latihan. Metode resitasi bisa digunakan oleh guru dalam pembelajaran menulis puisi. Diharapkan bagi peneliti selanjutnya, mengembangkan metode-metode pembelajaran yang lebih efektif dan inovatif dalam belajar mengajar.

\section{DAFTAR PUSTAKA}

Ahmadi, A. \& Supriyono W. (2004). Psikologi Belajar. Jakarta: Rineka Cipta.

Juidah, I. (2016). Efektivitas Metode Peta Pikiran Dalam Pembelajaran Menulis Teks Berita Siswa Kelas Viii Smpn 1 Widasari. Bahtera Indonesia; Jurnal Penelitian Bahasa Dan Sastra Indonesia.

https://doi.org/10.31943/bi.v1i1.46

Kasbolah (2001). Penelitian Tindakan Kelas. Jakarta: Bumi Aksara.

Niliawati, L, dkk. (2018). Penerapan Metode Circ (Cooperative Integrated Reading And Composition) Untuk Meningkatkan Kemampuan Membaca Pemahaman Siswa Kelas IV. Jurnal Pendidikan Guru Sekolah Dasar, 3(1), 23-34.
Nurudin. (2010). Dasar-Dasar Penulisan. Malang: UMM Press. Sampepolan, YA. (2019). Meningkatkan Hasil Belajar PKn pada Materi Nilai dan Norma Sosial Melalui Pembelajaran CIRC (Cooperative, Integrated, Reading, And

Composition) pada Siswa Kelas VIII2 SMP Negeri 1 Rantepao Toraja Utara. Jurnal Pemikiran dan Pengembangan Pembelajaran, 1(1), 130-139.

Samsudin, A. (2011). Peningkatan Kemampuan Menulis Eksposisi Berita dan Menulis Eksposisi Ilustrasi Siswa Kelas V Melalui Model Pembelajaran Kooperatif Terpadu Membaca dan Menulis.Jurnal Penelitian Pendidikan. 13 ( 2)1-9. Sanjaya. (2010). Penelitian Tindakan Sekolah. Jakarta: Kencana.

Saputri, dkk. (2016). Penerapan Metode Cooperative Integrated Reading And Composition Dengan Media Audio Visual Untuk Meningkatkan Kemampuan Menulis Teks Berita Pada Siswa Sekolah Menengah Pertama. BASASTRA Jurnal Penelitian Bahasa, Sastra Indonesia dan Pengajarannya. 4(2), 145-160.

Sugandi, A.( 2004). Teori Pembelajaran. Semarang: UNNES Press. Sujati. (2000). Penelitian Tindaka Kelas. Yogyakarta. FIP. UNY.

Sutisno, A. (2017). Efektivitas Metode Resitasi Pada Pembelajaran Menulis Puisi. Bahtera Indonesia; Jurnal Penelitian Bahasa Dan Sastra Indonesia.

https://doi.org/10.31943/bi.v2i1.39

Fakultas Keguruan dan Ilmu Pendidikan 
BAHTERA INDONESIA:

Yamin, M. (2007). Profesionalisasi Guru \&

Implementasi KTSP. Jakarta: Gaung. Persada Press.

Yusmiati, E. 2010. Penerapan Model Siklus Belajar Empiris Induktif Untuk Meningkatkan Aktivitas dan Penguasaan Konsep Larutan Elektrolit dan Reaksi. Bandar Lampung : Universitas Lampung 